\title{
O USO DO INSTRUMENTO AISHE NA GESTÃO PARA A SUSTENTABILIDADE EM UMA UNIVERSIDADE PÚBLICA
}

http://dx.doi.org/10.5902/2318133865694

\author{
Leandro Barreto de Souza ${ }^{1}$ \\ Renato de Almeida ${ }^{2}$ \\ Lidiane Mendes Kruschewsky Lordelo 3
}

\begin{abstract}
Resumo
As instituições de ensino superior são relevantes na formação de uma sociedade, dado ao seu papel na educação e difusão do conhecimento. A presente pesquisa avalia como a temática sustentabilidade vem sendo tratada em uma IES a partir da aplicação do instrumento Assessment Instrument for Sustainability in Higher Education - Aishe. Foi adotada a abordagem qualitativa e quantitativa, mediante análise de questionários aplicados a 42 coordenadores de curso de graduação do campus e gestores da administração central da Universidade Federal do Recôncavo da Bahia. O público-alvo atribuiu notas para 30 critérios distribuídos em cinco módulos, tornando possível avaliar e compreender a situação de sustentabilidade no campus. O módulo pesquisa apresentou o panorama mais crítico, enquanto o módulo sociedade foi o melhor avaliado. $O$ atual cenário decorre da existência de poucas iniciativas e ao seu limitado funcionamento, mas há uma perspectiva promissora, já que o novo PDI incorporou premissas e prazos compatíveis com a Agenda 2030.
\end{abstract}

Palavras-chave: desenvolvimento sustentável; ambientalização; identidade institucional.

\section{THE USE OF THE AISHE INSTRUMENT IN MANAGEMENT FOR SUSTAINABILITY IN A PUBLIC UNIVERSITY}

\begin{abstract}
Higher education institutions are relevant to the formation of a society, given their role in education and the dissemination of knowledge. This research evaluates how the Sustainability theme has been treated in an $\mathrm{HEI}$, based on the application of the instrument Assessment Instrument for Sustainability in Higher Education - Aishe. The qualitative and quantitative approach was adopted, through the analysis of questionnaires applied to 42 coordinators of the campus undergraduate courses and managers of the Universidade Federal do Recôncavo da Bahia. The target audience assigns scores for 30 criteria distributed in five modules, making it possible to assess and understand the sustainability situation on campus. The research module presented the most critical scenario, while the society module was the best evaluated. The current scenario results from the existence of few initiatives and their limited functioning; but there is a promising outlook, as the new PDI incorporated assumptions and deadlines compatible with the 2030 Agenda. Key-words: sustainable development; environmentalization; institutional Identity.
\end{abstract}

\footnotetext{
${ }^{1}$ Universidade Federal do Recôncavo da Bahia, Brasil. E-mail: barretoleo@ufrb.edu.br.

2 Universidade Federal do Recôncavo da Bahia, Brasil. E-mail: renato.almeida@ufrb.edu.br.

3 Universidade Federal do Recôncavo da Bahia, Brasil. E-mail: lidiane@ufrb.edu.br. 


\section{Introdução}

ma instituição de ensino superior deve pensar a produção do conhecimento e assumir, internamente, seu papel na construção de um projeto de sustentabilidade, sem negar o legado aos que passam por ela e que também usufruem do conhecimento e oportunidades geradas. A avaliação das políticas existentes e a incorporação de diretrizes institucionais são meios para se alcançar o posto de uma universidade sustentável. Este assunto vem ganhando notoriedade na administração pública por ser de sua competência promover a harmonia das relações entre os elementos humano, social, econômico e ambiental, principalmente nas universidades, espaço essencial na formação de profissionais, formadores de opinião e de ações inclusivas da comunidade acadêmica.

Torna-se, então, oportuno realizar diagnóstico sobre a responsabilidade das organizações frente à sustentabilidade a partir das interações com o meio em que habitam e praticam suas atividades, responsáveis ou não, definindo decisões e estratégias de gestão (Dotto e outros, 2019). Para Lozano (2006) é possível considerar distintos estágios de sustentabilidade em uma IES, de modo que o instrumento Assessment Instrument for Sustainability in Higher Education - Aishe - permite identificar o estágio atual e cenários desejáveis.

O presente estudo adotou o instrumento Aishe para avaliar o atual cenário de sustentabilidade do campus central de uma IES pública, federal, a partir da ótica dos seus gestores - administração central, coordenadores de curso, coordenadores administrativos - visando a traçar diretrizes futuras e escolher prioridades à gestão.

\section{Universidade sustentável}

Segundo Delors (2003) o ensino superior é indispensável e fundamental na transmissão de conhecimento cultural e científico gerado na atualidade. Por isso as IES estão em permanente reflexão e mudança do seu modo de pensar e agir para suprir necessidades do seu público-alvo, aperfeiçoando recursos utilizados na formação pedagógica discente, no desenvolvimento de habilidades ao processo de ensinoaprendizagem e, também, dando enfoque ao aprimoramento dos aspectos administrativos.

Nas últimas décadas a maior projeção da sustentabilidade nos cenários global e regional também pressionaram as universidades a um maior protagonismo e mudanças de pensamento no ambiente acadêmico. Para Disterheft e outros (2012) um campus sustentável entrelaça aspectos do ensino e da pesquisa com a gestão institucional, tendo a educação para a sustentabilidade enquanto fio condutor.

Para ajudar na compreensão de uma US Velazquez e outros (2006) afirmam que uma IES, como um todo ou em parte, deve buscar a promoção, regional ou global, para minimizar impactos ambientais, sociais, econômicos e à saúde gerados pelo uso dos seus recursos quando do cumprimento de suas funções de ensino-pesquisa-extensão e manutenção, ajudando na transição da sociedade para estilos de vida sustentáveis. 
Porém, institucionalizar a sustentabilidade requer empenho da gestão para defender e implantar mudanças. Comumente encontra o primeiro passo de forma top-down, devendo estimular adequações dos espaços físicos, procedimentos administrativos, reestruturação dos currículos e promover a educação para a sustentabilidade com 0 objetivo de redirecionar o pensamento dessa problemática.

As IES não devem ver a sustentabilidade como uma inovação radical, mas um caminho a ser trilhado no atual contexto global. Independente dos obstáculos a gestão é a responsável por difundir o compromisso com a sustentabilidade em suas ações e a partir de seus encaminhamentos que será ou não assumido pela comunidade uma nova direção.

Por fim, destaca-se que o conceito de US deve induzir atividades contínuas e duradouras nas áreas de educação, pesquisa, gestão do campus, extensão, avaliação, diretrizes institucionais e vivências de sustentabilidade no campus (Bizerril; Rosa; Carvalho, 2015). A compilação de estudos recentes realizada por Bizerril, Rosa e Carvalho (2018a) apontam aspectos que favorecem ou inibem a transição de mudanças na configuração da IES em uma US, fator que o instrumento Aishe pode auxiliar a identificar e direcionar as ações.

Dentre os aspectos que inibem a implementação e a institucionalização da sustentabilidade nas universidades destacam-se resistências pessoais às propostas de alteração; obstáculos institucionais às mudanças; falta de uma visão do conceito de sustentabilidade pela gestão; divergências na condução dos trabalhos em vista da institucionalização da sustentabilidade. Destacam-se entre os aspectos favoráveis: efetivar o compromisso da instituição com a causa; demonstrar o compromisso da gestão com o tema; estipular indicadores que avaliem o desempenho e relatem à comunidade; adotar a implementação participativa das mudanças.

\section{Assessment Instrument for Sustainability in Higher Education - Aishe}

Aishe é um instrumento que auxilia a busca pelo desenvolvimento sustentável (Roorda, 2009), elaborado para uso em universidades, campus, institutos, em projetos de ensino ou pesquisa e visa a ampliar a conscientização e envolvimento das pessoas frente ao tema da sustentabilidade a partir dos resultados obtidos pela definição de um plano de trabalho para alcançar elevado grau de sustentabilidade. Em linhas gerais Aishe pode ser aplicado de duas formas: como ferramenta externa, visando à certificação, ou como instrumento de auto-avaliação, como é o caso do presente trabalho.

O instrumento Aishe tem como propósito a melhoria contínua das ações desenvolvidas pela universidade, utilizando o Ciclo de Deming, também conhecido Ciclo PDCA. Está baseado no modelo EFQM Excelle de gestão de qualidade para desenvolver uma cultura de excelência, adotar boas práticas, conduzir a inovação e melhorar seus resultados.

A aplicabilidade do Aishe nas instituições permite avaliar como as operações, relações societárias, pesquisa e comunicação ampliam a visibilidade da gestão em vista de uma US. É adotada uma escala de cinco pontos para cada indicador apresentado - five stages mode - com base no modelo da Fundação Europeia de Gestão da Qualidade. A utilização do Aishe fornece informações sobre as ações mais eficazes para melhorar o nível de sustentabilidade da Universidade em cinco módulos distintos: 
Módulo identidade: estão descritas as características da IES, sua essência e natureza da organização. Destacam-se questões como: Quem somos nós? Por que fazemos as coisas que fazemos? Como podemos fazer uma diferença real no desenvolvimento sustentável? Seria correto nos descrevermos como uma organização sustentável?

Módulo de operações: descreve características práticas da organização. A universidade, ou parte dela, não é fundamentalmente diferente de qualquer outra organização, pois tratam cotidianamente de assuntos comparáveis: aquisição, gestão ambiental, investimentos, circunstâncias trabalhistas, respeito humano.

Módulo de educação: pode ser aplicado a institutos de ensino que não façam parte de uma universidade. Pretende verificar junto aos envolvidos qual o seu nível de conteúdo sobre o tema.

Módulo de pesquisa: pode ser aplicado a um instituto de pesquisa dentro de uma universidade para verificar o que é feito e quais os meios e esforços utilizados para que a pesquisa tenha destaque na sustentabilidade.

Módulo da sociedade: pode ser aplicado a qualquer nível ou unidade em que o módulo de educação ou o módulo de pesquisa foram aplicados. Busca entender e verificar a relação da IES com o público externo.

Cada um desses módulos compreende seis critérios, sendo possível atribuir valores mediante o uso da escala ordinal para obter uma visão geral da universidade. O estágio zero corresponde ao total desconhecimento ou não atendimento dos parâmetros analisados. O estágio 1 pressupõe a existência de práticas individuais e pontuais. 0 estágio 2 identifica ações comuns executadas no curto prazo. O estágio 3 representa intervenções sistêmicas de médio prazo, com avaliações de metas pré-estabelecidas. $O$ estágio 4 sugere ações de longo prazo que envolvam a comunidade externa e a comparação de resultados com outras instituições. O estágio 5 aponta ações de longo prazo, especialmente as intervenções internas e externas de destaque perante outras instituições. Embora tenha sido pensada para uma realidade europeia o Aishe já foi utilizado no Brasil, em estudos na Universidade de Passo Fundo (Brandli et al, 2011) e em outra IES da amazônia brasileira (Licório et al, 2018).

\section{Metodologia}

Este estudo tem cunho qualitativo e quantitativo. O lócus do estudo foi a Universidade Federal do Recôncavo da Bahia, criada em 2005, em modelo de multicampia. Atualmente conta com cerca de 12 mil estudantes de 64 cursos de graduação e 34 cursos de pós-graduação. Possui seis campi, mas o campus central, sediado em Cruz das Almas/BA, foi o escolhido para a realização do estudo, pois além de ser o maior, mais consolidado e antigo, possui o maior número de cursos, servidores e discentes, além de toda a gestão administrativa da IES.

Foram sujeitos da pesquisa os coordenadores dos cursos de graduação dos dois centros sediados no campus, dada a visão ampla da dinâmica institucional e dos projetos e programas desenvolvidos no âmbito dos seus cursos. Contudo, também foram envolvidos os coordenadores de setores administrativos e pró-reitores, permitindo melhor compreender a visão da equipe gestora da universidade a respeito da sustentabilidade no campus. Cabe destacar que o campus central é sede de 19 cursos de graduação, dois 
centros de ensino, cada um com diretor e vice-diretor, sete pró-reitorias, 21 coordenadores, além do reitor e vice, somando um universo amostral de 53 gestores participantes da pesquisa entre junho e agosto de 2019.

Foram adotadas as orientações de aplicação do instrumento Aishe 2.0, em que questionários impressos são respondidos, presencialmente, pelos sujeitos da pesquisa atribuindo notas crescente de 0 a 5 para cada critério. Junto a cada questionário foi compartilhada uma prancha especificando cada critério e nota para auxiliar na decisão. Ainda que processos históricos possam influenciar na decisão de cada nota, os sujeitos foram orientados a considerar o momento presente da instituição. Os 53 gestores foram convidados a responder o questionário in loco, com horário agendado. Objetivos e procedimentos foram apresentados antes da entrega dos questionários. O tempo de resposta variou de trinta a cinquenta minutos.

As folhas de resposta destes questionários foram tabuladas com o suporte do programa estatístico Stata 1.0, sendo possível processar as informações para análise, ou seja, verificar o estágio de sustentabilidade do campus central a partir da visão dos gestores. Adotou-se a mediana enquanto medida de tendência central. Essa etapa contou com a colaboração direta do dr. Niko Roorda, idealizador da ferramenta, que auxiliou na identificação dos pontos centrais. Os resultados obtidos foram confrontados com o plano de desenvolvimento institucional e os relatórios e informações publicados no sítio da IES. Isso permitiu apontamentos de diretrizes e sugestões de atividades à melhoria do status de sustentabilidade universitária.

\section{Descrição e análise dos dados}

O panorama de sustentabilidade no campus central foi elaborado com base nas respostas de 42 gestores que participaram da pesquisa, compreendendo 79,24\% do universo amostral. A abstenção de $20 \%$ foi interpretada como uma fragilidade institucional, dada a oportunidade de análise a partir da própria equipe de gestão.

Em linhas gerais o campus central apresenta um cenário elementar de sustentabilidade. A julgar pela representação das medianas se constatou que o módulo Sociedade teve o melhor resultado e o módulo Pesquisa apresentou o cenário mais crítico. Destaca-se que a análise individualizada dos diferentes módulos apenas considera a frequência com que os gestores indicaram notas da escala 0 a 5 para cada critério avaliado, tornando possível pormenorizar reflexões relevantes ao interesse da pesquisa. Constatou-se, em todos os 30 critérios analisados, a prevalência do estágio 1 na escala de sustentabilidade universitária.

\section{Módulo identidade}

O instrumento Aishe considera o Módulo Identidade como base a todos os demais módulos, pois retrata características fundamentais da IES e descreve a essência ou natureza da organização (Roorda, 2001). Essa concepção tem aderência ao conceito clássico defendido por Hatch; Schultz (2004), em que a identidade das organizações surge de aspectos centrais, distintivos e duradouros, com base nas crenças compartilhadas por seus membros. A centralidade identifica características essenciais da organização; a distinção destaca os elementos que distinguem uma organização das outras, e a continuidade temporal ressalta características estáveis no tempo. 
Em todos os critérios analisados no Módulo Identidade a prevalência das respostas dos gestores foi o estágio 1 , seguido pelos estágios 2 e 3 .

Figura 1 -

Frequência de respostas do módulo identidade.

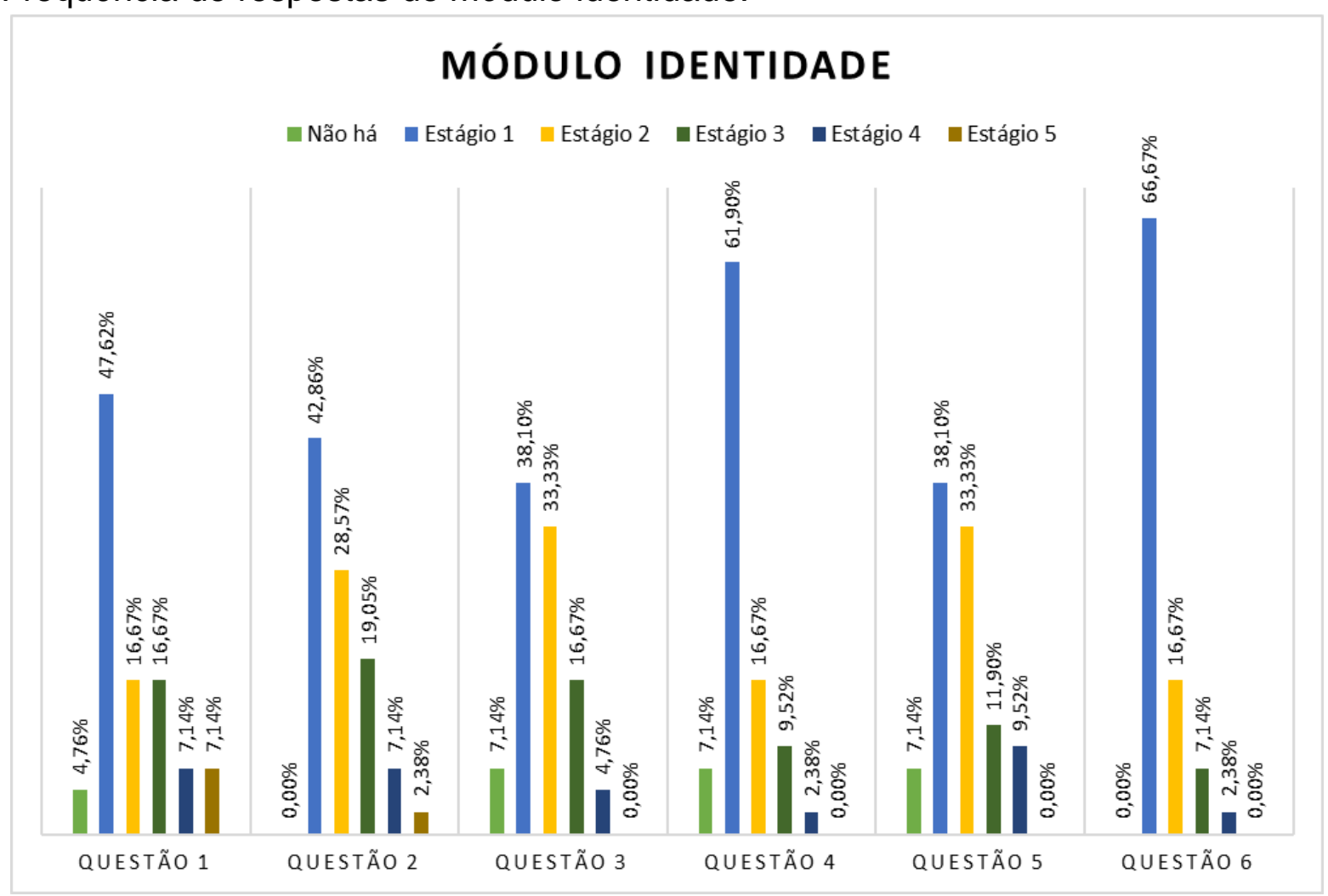

Fonte: autores.

Quadro 1 -

Critérios e questões do módulo identidade.

\begin{tabular}{|c|c|}
\hline Critério & Questão \\
\hline I.1 - Visão e Política & $\begin{array}{l}\text { A organização tem uma visão baseada no desenvolvimento sustentável } \\
\text { e em responsabilidade social, em aspectos relacionados as áreas de } \\
\text { especialização e as consequências disso para a política da } \\
\text { organização. A visão é mostrada na política. Essa política traduz a } \\
\text { visão em planos concretos de ação. Metas são formuladas e atividades } \\
\text { são planejadas com o objetivo de concretizar essas metas. }\end{array}$ \\
\hline I.2 - Liderança & $\begin{array}{l}\text { A gestão não é apenas o responsável formal pela integração do } \\
\text { desenvolvimento sustentável na visão da organização e atividades. Ela } \\
\text { também lidera, por exemplo, mostrando envolvimento pessoal. Isso } \\
\text { acaba inspirando os funcionários, estudantes e possivelmente outros } \\
\text { colaboradores. A gestão ouve atentamente eles, usa suas ideias e } \\
\text { opiniões e pede retorno sobre seu funcionamento. Assim, a gestão usa } \\
\text { sua autoridade de uma forma participativa genuína. }\end{array}$ \\
\hline I.3 - Comunicação & $\begin{array}{l}\text { Existe divulgação sobre o desenvolvimento sustentável da } \\
\text { organização, dentro da própria organização e com o mundo exterior. A } \\
\text { comunicação é usada para reforçar a visão sobre o desenvolvimento } \\
\text { sustentável, para incentivar novas iniciativas, e para informar e receber }\end{array}$ \\
\hline
\end{tabular}




\begin{tabular}{|l|l|}
\hline I.4 - Especialistas & $\begin{array}{l}\text { um retorno de todos os tipos de colaboradores, por exemplo: } \\
\text { funcionários, estudantes, campo profissional, colaboradores diretos e } \\
\text { sociedade em geral. }\end{array}$ \\
\hline $\begin{array}{l}\text { Os especialistas sobre desenvolvimento sustentável disponíveis na } \\
\text { organização são atualizados e em número suficiente para trabalhar } \\
\text { ativamente na integração e melhoria do desenvolvimento sustentável } \\
\text { na visão e atividades da organização. Até certo ponto, esses } \\
\text { especialistas estão disponíveis dentro do grupo de funcionários da } \\
\text { organização. Além disso, uma rede externa está funcionando com o } \\
\text { objetivo de utilizar os especialistas disponíveis fora da universidade. }\end{array}$ \\
\hline I.5- Coerência & $\begin{array}{l}\text { Uma universidade pode contribuir para o desenvolvimento sustentável } \\
\text { de várias formas: pela educação, pesquisa, sua forma de operação e } \\
\text { sua contribuição direta para a sociedade. Esses vários papéis podem } \\
\text { ser reforçados uns pelos outros se houver cooperação entre eles. Por } \\
\text { exemplo, o campus pode ser usado como uma ferramenta para a } \\
\text { educação, pesquisa e interações sociais. Os estudantes podem } \\
\text { contribuir com uma pesquisa sustentável e para o desenvolvimento da } \\
\text { comunidade. Coerência entre os papeis permite que a instituição } \\
\text { "pratique o que prega". }\end{array}$ \\
\hline $\begin{array}{l}\text { I.6 - Transparência e } \\
\text { responsabilidade }\end{array}$ & $\begin{array}{l}\text { A instituição reporta para seus colaboradores sobre suas atividades e } \\
\text { seus resultados sobre o desenvolvimento sustentável de uma forma } \\
\text { transparente e assim presta contas para os seus colaboradores, } \\
\text { incluindo a sociedade como um todo. }\end{array}$ \\
\hline
\end{tabular}

Fonte: Roorda (2009).

Quanto ao Critério I.1 Visão e política, grande parte dos gestores acredita que a IES está no Estágio 1, pois embora exista uma gestão baseada no desenvolvimento sustentável e na responsabilidade social, não há um envolvimento dos servidores e discentes, além da ausência de integração da visão institucional com o seu papel na sociedade a longo prazo. Além disso, quando existem, as políticas de desenvolvimento sustentável são direcionadas apenas pelo modelo top-down. Portanto, o resultado sugere que a IES ainda está em fase inicial de construção de sua identidade sustentável. De outra forma notas elevadas representadas pelos estágios 3, 4 ou 5 somaram quase $31 \%$ e confirmam ser esse critério uns dos mais reveladores, entre aqueles previstos no instrumento Aishe.

No critério I.2, que trata da Liderança, a gestão expressada por meio da sua visão e ação institucional acaba inspirando funcionários, estudantes e possivelmente outros colaboradores a se envolverem no assunto, mas $42,86 \%$ ainda consideram a IES no Estágio 1, pois a preocupação dos gestores com o desenvolvimento sustentável e o envolvimento dos funcionários é ocasional. Outros 28,57\% apontaram a IES no Estágio 2, quando além de ouvir atentamente a opinião dos funcionários e estudantes a gestão responde com iniciativas.

O critério I.3 aborda como a Comunicação interna é utilizada em prol da sustentabilidade na universidade. Dos 42 gestores participantes 38,10\% apontaram a IES no Estágio 1, já que as informações são normalmente obtidas por iniciativa própria, individual. Outros 33,33\% sugeriram o Estágio 2, ao afirmarem que o assunto pode aparecer em reuniões e eventos, mas faltam publicações específicas.

\begin{tabular}{|l|l|l|l|l|l|}
\hline Regae: Rev. Gest. Aval. Educ. & Santa Maria & v. 10 & n. 19 & e65694, p. 1-22 & 2021 \\
\hline
\end{tabular}


No critério I.4, que trata dos Especialistas, 61,90\% consideram a IES no Estágio 1, ou seja, embora estejam à disposição para execução de projetos, não há um plano sistematizado para que sejam colaboradores direto da universidade, dada a inexistência de organização para envolvê-los na dinâmica do campus. E assim predominam as iniciativas individuais.

O critério 1.5 trata da Coerência na instituição frente à práxis do tripé ensinopesquisa-extensão e se esses vários papéis podem ser mutuamente reforçados. Constatou-se leve variação no pensamento, já que 38,10\% apontaram a IES no Estágio 1 e 33,33\% consideram-na no Estágio 2, com sinais de integração entre os papéis da IES, além de incentivos para que sejam praticadas ações sustentáveis.

Pelo menos $66 \%$ dos gestores ainda veem o Critério 1.6 Transparência e responsabilidade no Estágio 1. Este foi o critério que recebeu a mais alta frequência de respostas, mesmo quando comparado a outros módulos. Ocasionalmente a gestão fornece informações sobre os resultados e metas ligadas à sustentabilidade, ainda que limitadas a um grupo de funcionários dentro da organização. Consequentemente há descrédito com a transparência das atividades e atos. Não há um retorno sistematizado da gestão sobre as sugestões apontadas em relatórios, nem mesmo um momento para escutar a comunidade sobre suas propostas de aperfeiçoamento daquilo já implementado.

\section{Módulo operações}

O Módulo operações se relaciona com as dimensões ligadas ao bom desempenho da sustentabilidade universitária. Para Velazquez e outros (2006) uma universidade sustentável deve se comprometer, minimamente, com a geração de impactos ambientais, sociais, econômicos e de saúde que decorrerem da sua atividade, mas também pelo fato de que a uma IES interessa contribuir com a comunidade durante o processo de adoção de posturas sustentáveis. Portanto, todas as operações do campus devem ser observadas.

Todos os critérios do Módulo operações apresentaram prevalência de indicação ao estágio 1 , embora algumas vezes o estágio 0 , total ausência até mesmo de atividades individuais, também tenha sido muito frequente. 
Figura 1 -

Frequência de respostas do módulo operações.

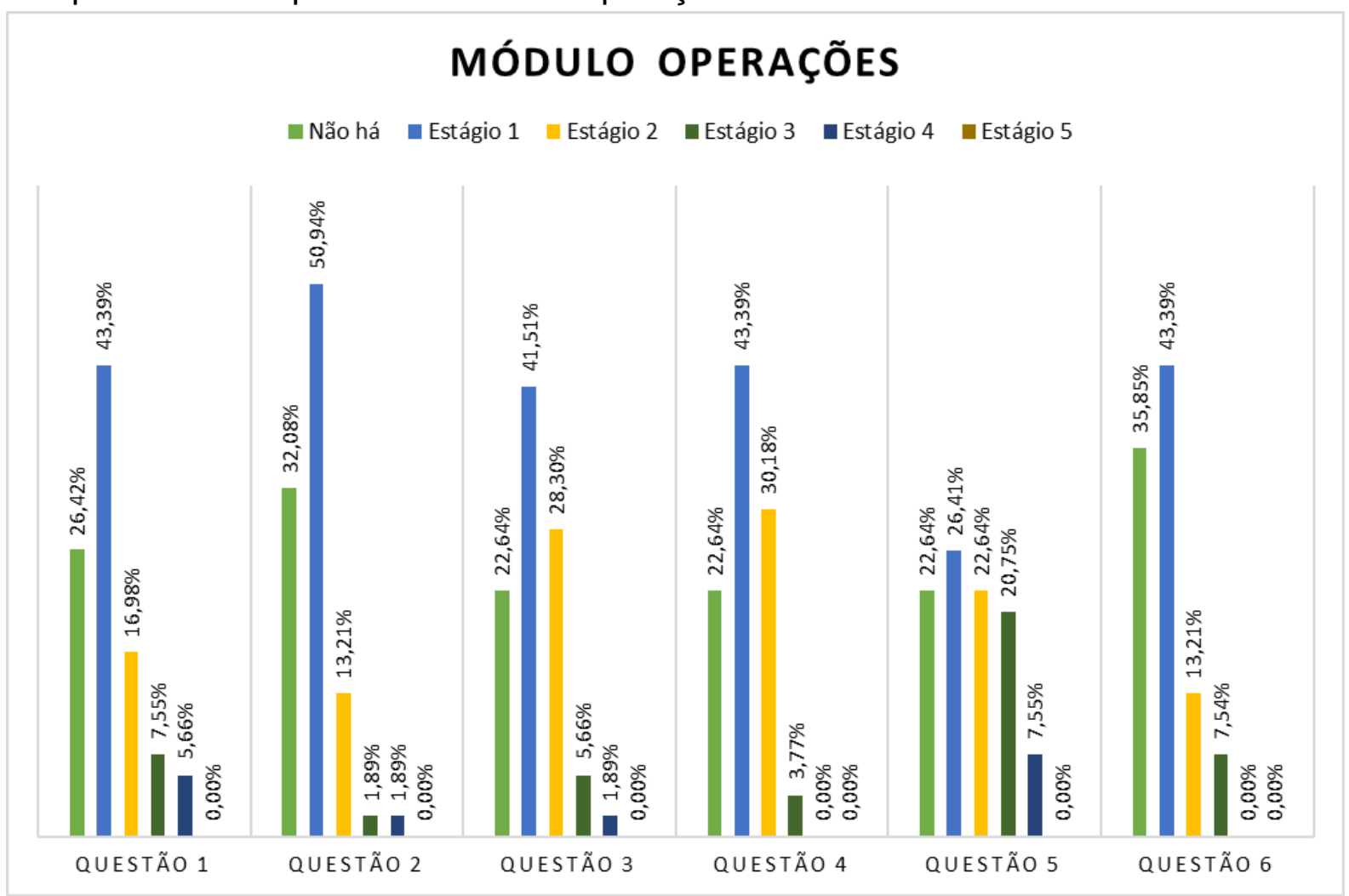

Fonte: autores.

Quadro 2 -

Critérios e questões do Módulo Operações.

\begin{tabular}{|l|l|}
\hline \multicolumn{1}{|c|}{ Critério } & \multicolumn{1}{c|}{ Questão } \\
\hline O.1 - Metas & $\begin{array}{l}\text { A organização estabeleceu metas de operação, com o objetivo de } \\
\text { satisfazer as demandas do desenvolvimento sustentável. }\end{array}$ \\
\hline $\begin{array}{l}\text { O.2 - Estrutura } \\
\text { física }\end{array}$ & $\begin{array}{l}\text { Os elementos físicos de longa duração da organização, como os prédios, } \\
\text { infraestrutura e habitat natural, funcionam bem de um ponto de vista } \\
\text { sustentável, porque eles são mantidos sustentáveis ou mesmo planejados } \\
\text { para serem. }\end{array}$ \\
\hline O.3 - Economia & $\begin{array}{l}\text { Em situações onde assuntos econômicos ou financeiros são relevantes, } \\
\text { demandas baseadas no desenvolvimento sustentável são consideradas em } \\
\text { aspectos como: desenvolvimento da estratégia ou política, decisões } \\
\text { operacionais e ações, para comunicar e reportar as finanças. }\end{array}$ \\
\hline O.4 - Ecologia & $\begin{array}{l}\text { A organização minimiza seus impactos negativos no meio ambiente ou, em } \\
\text { alguns aspectos, tem uma contribuição positiva para o meio. }\end{array}$ \\
\hline O.5 - Humanidade & $\begin{array}{l}\text { A organização preocupa-se com isso e as condições de trabalho e vida } \\
\text { para seus funcionários e estudantes são seguras, justas e saudáveis. }\end{array}$ \\
\hline $\begin{array}{l}\text { O.6 - Avaliação } \\
\text { da qualidade }\end{array}$ & $\begin{array}{l}\text { O desempenho operacional é sustentavelmente otimizado por um sistema } \\
\text { de medidas, avaliações e melhorias contínuas. }\end{array}$ \\
\hline
\end{tabular}

Fonte: Roorda (2009). 
O Critério 0.1 identifica metas de operações definidas pela IES para atender demandas de sustentabilidade. Quase a metade dos questionários $(43,39 \%)$ apontou apenas a existência de poucos aspectos sobre sustentabilidade claramente percebidos, mas sem um documento operacional de orientação multidisciplinar: estágio 1. Portanto, deve-se buscar a consolidação de uma política operacional de sustentabilidade, com avaliações e ajustes periódicos.

O Critério 0.2 aborda a Estrutura física da universidade, especialmente sobre como os prédios são pensados e concebidos numa lógica sustentável ou mesmo como são planejados para serem funcionais. Mais de $50 \%$ dos gestores acreditam que a IES esteja no estágio 1 , pois são poucos ou raros os aspectos sustentáveis utilizados nas construções. Mas aqui há uma perspectiva que merece ser incentivada, já que podem ser realizadas parcerias com os cursos de Engenharia Civil e Engenharia Ambiental sediados no próprio campus analisado. Isso pode ajudar a promover adequações orientadas nas construções já existentes e propor futuras construções mais sustentáveis. Cabe ressaltar que, atualmente, por iniciativa de algumas universidades, há destinação de parte do orçamento exclusivo para alavancar ações ambientais e sustentáveis em suas IES.

O Critério 0.3 avalia se as decisões que envolvem assuntos econômicos ou financeiros consideram a relevância do desenvolvimento sustentável. A maior parte dos gestores apontou o estágio 1 , já que as decisões são tomadas de modo acidental e individual, na tentativa de aumentar a eficiência energética e reduzir o consumo de materiais.

O Critério 0.4 analisa a Ecologia no campus e as estratégias adotadas para minimizar impactos negativos no meio ambiente ou como ela contribui de forma positiva para o cuidado. Prevaleceu a opinião $(43,39 \%)$ de que as iniciativas partem de intervenções individuais ou isoladas, não havendo um plano que envolva a comunidade em assuntos ligados ao meio ambiente. Nem mesmo há um sistema integrado de gestão ambiental para monitorar o campus, de modo que a avaliação, quando ocorre, está relacionada ao setor que coordena a ação.

O Critério 0.5 oferece atenção às condições de trabalho e vida, se elas são seguras, justas e saudáveis aos seus funcionários e estudantes. Houve variação entre $20 \%$ e $26 \%$ para as notas $0,1,2$ e 3: há quem considere inexistente qualquer preocupação com as condições de vida e trabalho, mas também há quem considere existir igualdade das condições de trabalho, proteção contra assédios e ameaças à saúde, além de liberdade de expressão.

O critério 0.6 aborda a Avaliação da qualidade e 35\% dos gestores atribuíram nota zero a esta questão, ratificando ser urgente um firme posicionamento para que a sustentabilidade seja incorporada em todos os espaços. De outra forma $43,39 \%$ entenderam que a IES está no estágio 1, pois somente alguns poucos indicadores foram formulados e usados individualmente.

Vale destacar que parte do campus analisado aproveitou estruturas prediais com quase 70 anos e que necessitam de periódicas reformas hidráulicas, elétricas e adequação ao propósito didático. Urge a adoção de um sistema de gestão ambiental eficaz para minimizar impactos e direcionar decisões. O próprio Ministério do Meio Ambiente desenvolveu o programa Agenda Ambiental na Administração Pública (A3P), que visa a mudança da cultura organizacional, das entidades públicas, com a inserção de

\begin{tabular}{|l|l|l|l|l|l|}
\hline Regae: Rev. Gest. Aval. Educ. & Santa Maria & v. 10 & n. 19 & e65694, p. 1-22 & 2021 \\
\hline
\end{tabular}


critérios de responsabilidade socioambiental nas atividades administrativas para o alcance da sustentabilidade. Se adotado vários eixos temáticos da A3P podem contribuir com ganhos ao Módulo Operações. Algumas IES de tamanho e estrutura similar têm adotado este modelo para avaliar práticas de gestão ambiental, já contabilizando melhorias do ambiente construído - iluminação, ventilação natural e acessibilidade - (Araújo; Freitas; Rocha, 2017). Constatou-se que a IES analisada não implantou o programa A3P e que um plano de logística sustentável foi elaborado, mas sua versão final ainda não está consolidada.

\section{Módulo ensino}

O Módulo ensino pode ser aplicado na Universidade como um todo ou a um único curso, departamento ou Centro (Roorda, 2009). Na prática visa a identificar se os princípios do desenvolvimento sustentável estão integrados ao currículo, aproximando-se do conceito de ambientalização curricular.

A ambientalização nas universidades é um dos caminhos mais indicados para alcançar a sustentabilidade, podendo ocorrer por motivos internos - iniciativas docentes e discentes, filosofia da práxis curricular, apoio institucional dos tomadores de decisão e de uma política institucional -; ou motivos externos: pressão da mídia e da opinião pública por melhor contextualização local/regional e apontamento de soluções e experiências que envolvam a sociedade civil) (Marcomim; Silva, 2009).

A ambientalização deve ir além da abordagem curricular ou das práticas de ensino. Daí a defesa de uma concepção sistêmica em que a ambientalização não pode ser restrita a mudança de conteúdo, metodologia, materiais ou atividades, mas também mudanças na estrutura organizacional, na capacitação docente, na avaliação de processos educativos e seus resultados, além de mudanças institucionais na infraestrutura e normas de funcionamento (Kitzmann; Asmus, 2012).

A opinião geral dos gestores sobre o Módulo ensino apontou uma percepção geral ainda estagnada no estágio 1, basicamente orientado por atividades em detrimento de processos, sistemas e sociedade. 
Figura 3 -

Frequência de respostas do módulo ensino.

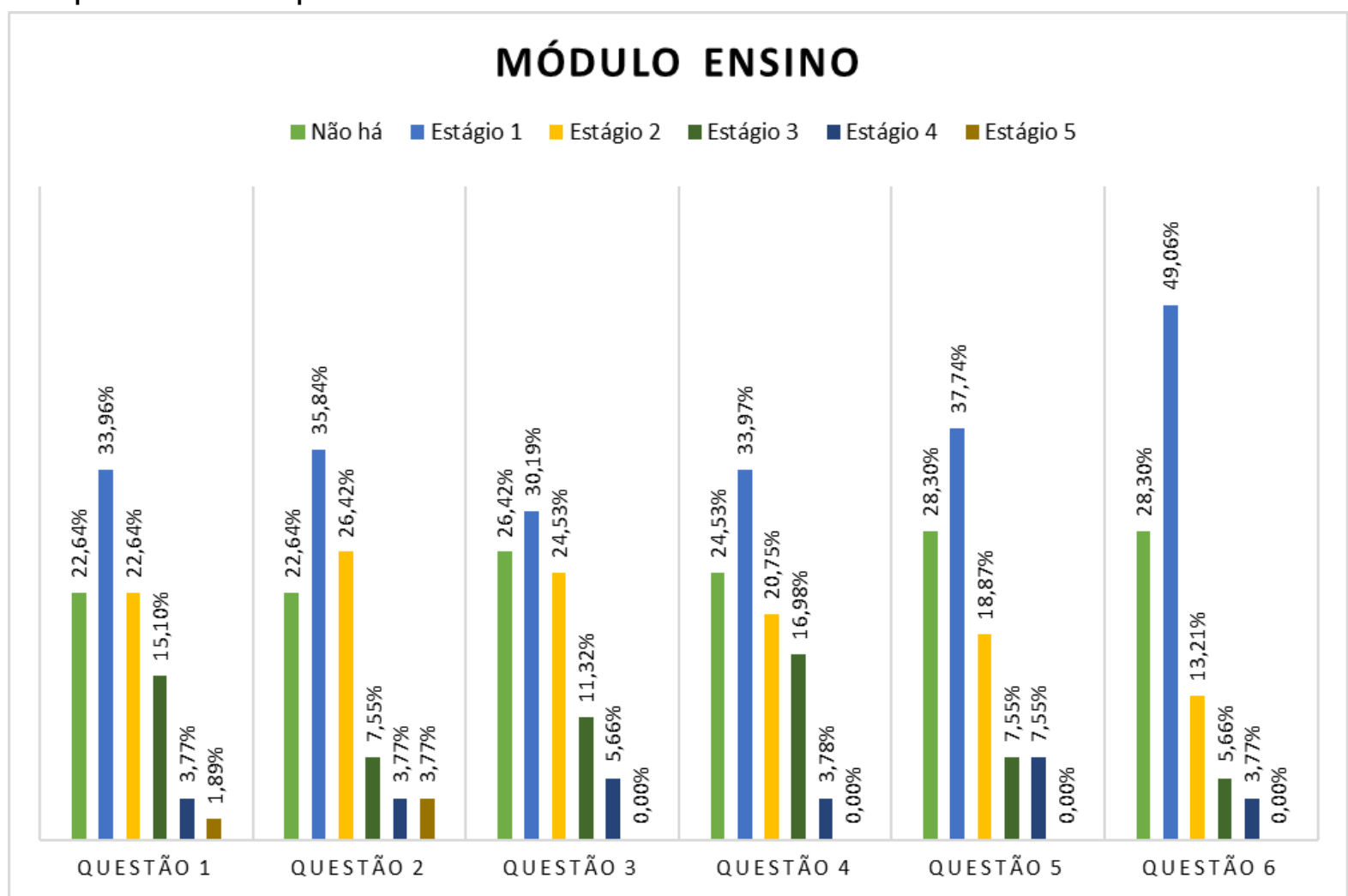

Fonte: autores.

Quadro 3 -

Critérios e questões do módulo ensino.

\begin{tabular}{|l|l|}
\hline \multicolumn{1}{|c|}{ Critério } & \multicolumn{1}{c|}{ Questão } \\
\hline E.1 - Metas & $\begin{array}{l}\text { O perfil do graduado determina as metas da educação, ou seja, a } \\
\text { caracterização do profissional que se forma e vai para o campo de } \\
\text { trabalho. Muitos termos são usados para o perfil do graduado, por } \\
\text { exemplo: "metas educacionais do programa", "perfil do profissional", } \\
\text { "qualificações acadêmicas", "competências profissionais" e etc. }\end{array}$ \\
\hline E.2 - Metodologia & $\begin{array}{l}\text { Algumas metodologias são mais cabíveis que outras para se adquirir } \\
\text { habilidades, conhecimentos e atitudes, relacionadas ao desenvolvimento } \\
\text { sustentável. Por exemplo, aumentar ou reforçar a responsabilidade } \\
\text { pessoal dos futuros profissionais não será fácil quando a atividade do } \\
\text { estudante se limita a ouvir passivamente ao professor durante as aulas. } \\
\text { Idealmente, o currículo deve consistir em uma variedade de } \\
\text { metodologias educacionais, combinadas com as características do perfil } \\
\text { do graduado. }\end{array}$ \\
\hline $\begin{array}{l}\text { E.3 - Sensibilização } \\
\text { e conceitos básicos }\end{array}$ & $\begin{array}{l}\text { Uma introdução ao desenvolvimento sustentável é passada no começo } \\
\text { do currículo. Os conceitos básicos do desenvolvimento sustentável são } \\
\text { abordados, assim como as suas relações. Essa introdução pode ser } \\
\text { dada na forma de um curso básico, com a duração de alguns dias ou } \\
\text { semanas. Alternativamente, pode ser separado por um longo período, } \\
\text { como uma nova matéria ou integrada em uma ou mais matérias } \\
\text { existentes. }\end{array}$ \\
\hline
\end{tabular}




\begin{tabular}{|l|l|}
\hline $\begin{array}{l}\text { E.4 - Integração } \\
\text { temática }\end{array}$ & $\begin{array}{l}\text { No decorrer do currículo, assuntos relacionados ao desenvolvimento } \\
\text { sustentável são abordados. A maioria deles tem uma forte relação com } \\
\text { as disciplinas, apesar de que outros assuntos podem ser apresentados } \\
\text { também. }\end{array}$ \\
\hline $\begin{array}{l}\text { E.5 - Integração } \\
\text { interdisciplinar }\end{array}$ & $\begin{array}{l}\text { Os vários assuntos relacionados a sustentabilidade no currículo são } \\
\text { relacionados de várias formas: intradisciplinarmente (dentro da própria } \\
\text { disciplina), multidisciplinariamente (combinando um número de } \\
\text { disciplinas por meio de um ou mais estudantes desta disciplina), } \\
\text { interdisciplinariamente (com cooperação real entre estudantes e } \\
\text { profissionais de áreas diferentes), ou mesmo transdisciplinariamente } \\
\text { (também com a cooperação dos stakeholders). }\end{array}$ \\
\hline $\begin{array}{l}\text { E.6 - Avaliação da } \\
\text { produção }\end{array}$ & $\begin{array}{l}\text { A integração do desenvolvimento sustentável no currículo resulta em } \\
\text { graduados onde a presença do desenvolvimento sustentável pode ser } \\
\text { percebida, dessa forma mostrando que o curso está contribuindo de } \\
\text { forma evidente para o desenvolvimento sustentável. }\end{array}$ \\
\hline
\end{tabular}

Fonte: Roorda (2009).

O critério E.1 trata do perfil do egresso na IES e se as habilidades e competências direcionadas ao desenvolvimento sustentável estão presentes em sua formação, ou se são demandados a terem capacidades multidisciplinares ao assumirem seus cargos no mercado de trabalho. Para 33,96\% dos gestores a IES está no estágio 1, sendo possível perceber apenas algumas poucas atividades direcionadas ao desenvolvimento sustentável na formação dos discentes que concluem o ensino superior.

No critério E.2 os gestores responderam sobre as metodologias utilizadas para adquirir habilidades, conhecimentos e atitudes ligadas ao desenvolvimento sustentável. Mais de $35 \%$ apontaram o estágio 1, pois as estratégias metodológicas ainda são tratadas de forma pontual para simular uma aprendizagem ativa e significativa. Ressalta-se que $26 \%$ apontaram estágio 2 , pois identificaram processos curriculares direcionados a selecionar metodologias capazes de simular inovação: estímulo da criatividade e capacidade de lidar com situações inusitadas.

Os critérios E.3, E.4 e E.5 tratam, respectivamente, das iniciativas de sensibilização acadêmica institucional para o desenvolvimento sustentável, a integração temática aos diferentes componentes curriculares e o nível de integração interdisciplinar. Para mais da metade dos gestores cada um dos três critérios são ausentes ou típicos do estágio 1. A sensibilização até pode ocorrer no início dos cursos, mas nem sempre decorre de um planejamento ligando o tema a outros assuntos do currículo. As atividades de integração temática são fragmentadas ou pontuais. Algum nível de integração eventualmente é alcançado dentro dos processos de aprendizagem, quando são conectadas as abordagens analíticas e holísticas ou do local ao global, mas ainda distantes das práticas interdisciplinares ou transdisciplinares, tão caras ao tema da sustentabilidade.

O critério E.6 aborda a Avaliação da produção, tentando identificar a produção sobre a temática sustentabilidade entre os graduandos até o momento da conclusão do curso. Para 49\% dos gestores existe, minimamente, uma organização de projetos e trabalhos de graduação ligados ao assunto, mas não foi encontrado qualquer repositório institucional dessa produção. 
Segundo Almeida et al (2019) este mesmo campus universitário reúne quase a totalidade dos cursos de engenharia da IES. Ali constam cerca de 650 componentes curriculares ofertados semestralmente aos estudantes da graduação. Porém, apenas sete componentes abordam explicitamente conteúdos de educação ambiental, sustentabilidade, ética e gestão ambiental.

\section{Módulo pesquisa}

Este módulo tem os mesmos critérios do Módulo ensino, mas com foco voltado à pesquisas desenvolvidas na IES. Como anteriormente mencionado o Módulo pesquisa apresentou o cenário mais frágil entre todos analisados. A universidade deveria ensinar e criar condições para que discentes, técnicos e docentes façam pesquisas sobre sustentabilidade, pois são tímidas as publicações e iniciativas. Parece haver descompasso entre aquilo ensinado em sala de aula, as pesquisas em laboratórios e as atividades acadêmicas, institucionais e administrativas do campus. Prevaleceram, em todos os indicadores, o estágio 1, seguido do estágio 0 : ausência de atividades ou esforços.

Figura 4 -

Frequência de respostas do módulo pesquisa.

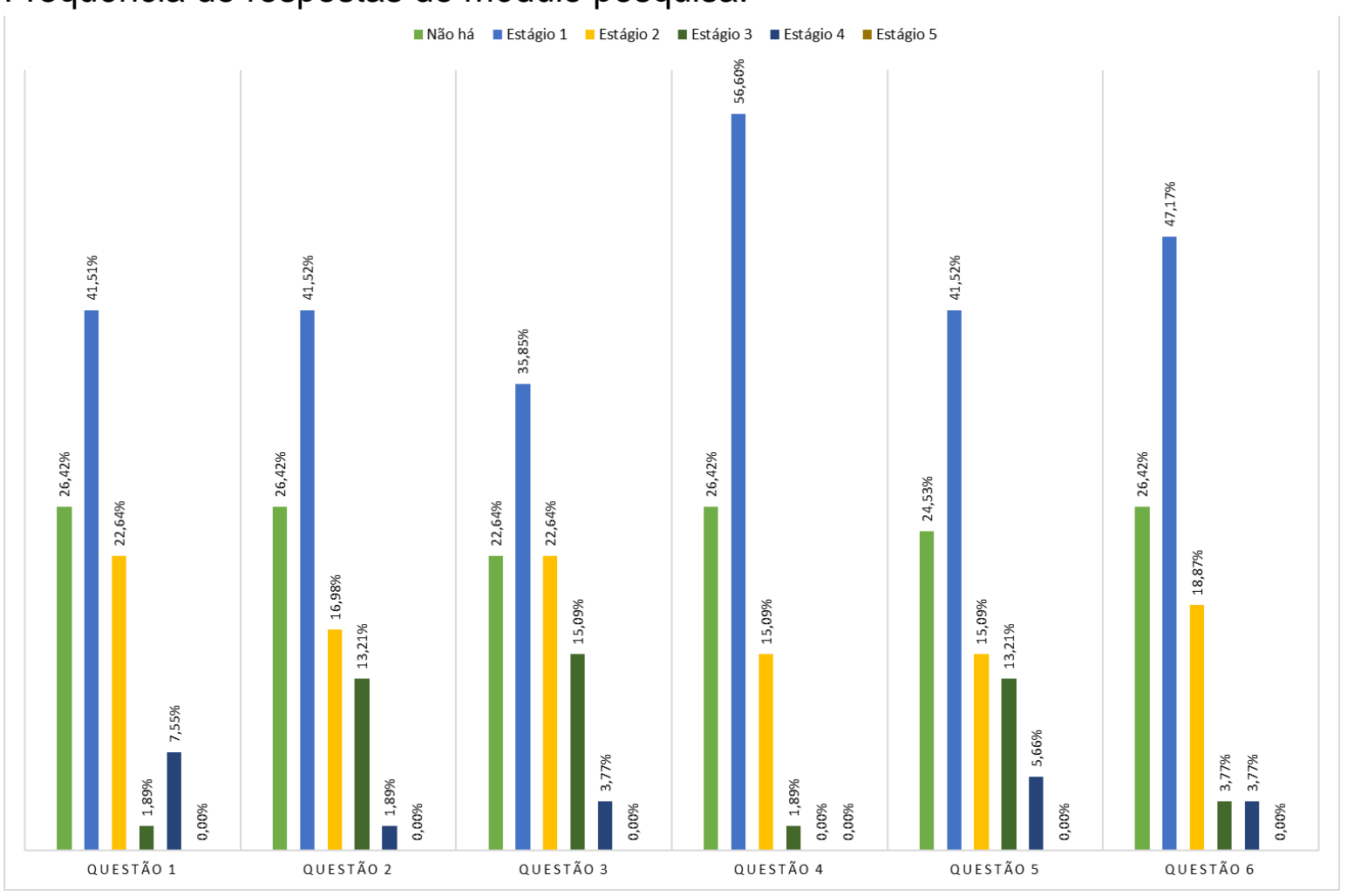

Fonte: autores. 
Quadro 4 -

Critérios e questões do módulo pesquisa.

\begin{tabular}{|c|c|}
\hline Critério & Questão \\
\hline P.1 - Metas & $\begin{array}{l}\text { Em suas metas, estratégia e política, a atenção da organização é voltada } \\
\text { para o desenvolvimento sustentável. Em estágios mais baixos, essa } \\
\text { atenção é apenas mais uma entre outros focos de atenção. Nos estágios } \\
\text { mais elevados, o desenvolvimento sustentável é o foco principal (ou pelo } \\
\text { menos um dos focos principais) da pesquisa, como a pesquisa é } \\
\text { projetada com o objetivo explícito de contribuir para o desenvolvimento } \\
\text { sustentável. }\end{array}$ \\
\hline P.2 - Metodologia & $\begin{array}{l}\text { A metodologia cientifica é projetada de uma forma que permite ou reforça } \\
\text { contribuições para a ciência da sustentabilidade. }\end{array}$ \\
\hline $\begin{array}{l}\text { P.3 - Sensibilização } \\
\text { e conceitos básicos }\end{array}$ & $\begin{array}{l}\text { A organização e seus pesquisadores têm uma percepção clara da } \\
\text { relevância do desenvolvimento sustentável, tanto relacionado à sociedade } \\
\text { e natureza, quanto a sua relação com a própria pesquisa. Os } \\
\text { pesquisadores possuem um conhecimento e uma compreensão claros } \\
\text { sobre os conceitos básicos do desenvolvimento sustentável e tem a } \\
\text { habilidade de relacionar eles com o trabalho que realizam. }\end{array}$ \\
\hline $\begin{array}{l}\text { P.4 - Integração } \\
\text { temática }\end{array}$ & $\begin{array}{l}\text { Temas e questões do desenvolvimento sustentável estão integrados a } \\
\text { pesquisa. }\end{array}$ \\
\hline $\begin{array}{l}\text { P.5 - Integração } \\
\text { interdisciplinar }\end{array}$ & $\begin{array}{l}\text { Os vários temas e aspectos da sustentabilidade são integrados na } \\
\text { pesquisa em sua total complexidade de relações e interações mútuas. A } \\
\text { integração também é alcançada por meio de cooperação com outros } \\
\text { institutos de pesquisa e organizações sociais. }\end{array}$ \\
\hline $\begin{array}{l}\text { P.6 - Avaliação da } \\
\text { produção }\end{array}$ & $\begin{array}{l}\text { A integração do desenvolvimento sustentável nos resultados das } \\
\text { pesquisas, nos relatórios científicos e apresentações pode ser notada, } \\
\text { assim é provado que a pesquisa está contribuindo de forma evidente para } \\
\text { o desenvolvimento sustentável. }\end{array}$ \\
\hline
\end{tabular}

Fonte: Roorda (2009).

O critério P.1 trata da prioridade política - metas e estratégias - que a organização oferece às pesquisas voltadas ao desenvolvimento sustentável. Para $26,42 \%$ dos gestores não há incentivo e $41 \%$ consideram a IES no estágio 1. Então, 67\% atribuíram nota baixa a este critério, colocando-o entre um dos pontos a serem discutidos ao aprimoramento da gestão.

No critério P.2 o resultado foi similar à questão anterior. Há necessidade de uma mudança de paradigma metodológico na própria produção científica, migrando de um modelo acadêmico e mono-disciplinar ao modelo interdisciplinar, em que pesquisadores trabalham em rede, de forma ampla na produção de conhecimento. Cabe destacar que $13 \%$ dos gestores já enxergam essa mudança de paradigma de forma sistêmica na IES, estágio 3. Isso, certamente, tem maior significado aos gestores envolvidos em programas de pós-graduação.

Tal como no Módulo ensino os critérios P.3, P.4 e P.5 estão correlacionados, respectivamente, à sensibilização acadêmica institucional para o desenvolvimento sustentável; sua integração temática e o nível de integração interdisciplinar dentro das pesquisa. Em todos os critérios prevaleceram notas baixas: total ausência de esforços ou

\begin{tabular}{|l|l|l|l|l|l|}
\hline Regae: Rev. Gest. Aval. Educ. & Santa Maria & v. 10 & n. 19 & e65694, p. 1-22 & 2021 \\
\hline
\end{tabular} 
estágio 1. Os gestores reconhecem que alguns pesquisadores incorporam o conceito de desenvolvimento sustentável em seus projetos e até tenham ciência da relevância de suas pesquisas frente a essa temática, embora distantes de uma sólida cooperação com colaboradores e com a sociedade. Isso também é verdade para a integração interdisciplinar, que deve ampliar a cooperação junto a outros institutos de pesquisa. Pelo menos 19\% dos gestores apontaram notas altas, estágios 3 e 4, mas esse desejável esforço de integração interdisciplinar, critério P.5, novamente deve ter maior significado aos gestores ligados aos programas de pós-graduação.

Sobre a Avaliação da produção, critério P.6, é analisada se há evidente integração dos resultados de pesquisas sobre desenvolvimento sustentável em relatórios e apresentações. Para $73 \%$ as iniciativas são ausentes, estágio 0 , ou baseadas em ações individuais de divulgação dos resultados, estágio 1. Nos últimos anos há tentativa de ampliar a visibilidade das pesquisas desenvolvidas na IES por meio da produção de vídeos e divulgação em mídia institucional.

O Módulo pesquisa demonstrou ser o mais frágil segundo a avaliação dos gestores, embora existam pesquisadores e grupos de pesquisa fortemente empenhados em seus programas de pós-graduação na IES. Esse empenho precisa se expandir também aos cursos de graduação. A Capes vem exigindo maior interação entre os dois níveis formativos por meio do indicador de integração acadêmica. Esse esforço de aproximação pode ser aprimorado pela indução de atividades específicas direcionadas aos programas institucionais.

\section{Módulo sociedade}

O Módulo sociedade é aquele que apresentou o melhor resultado na IES. Em linhas gerais os critérios adotados pelo instrumento Aishe se aproximam do conceito de extensão universitária no Brasil e, de alguma forma, estão alicerçados no tripé ensino, pesquisa e extensão. As notas baixas - estágio 0 e 1 - continuaram evidentes, mas os estágios 3 e 4 também foram reconhecidos e ajudaram a equilibrar o panorama deste módulo. 
Figura 5 -

Frequência de respostas do módulo sociedade.

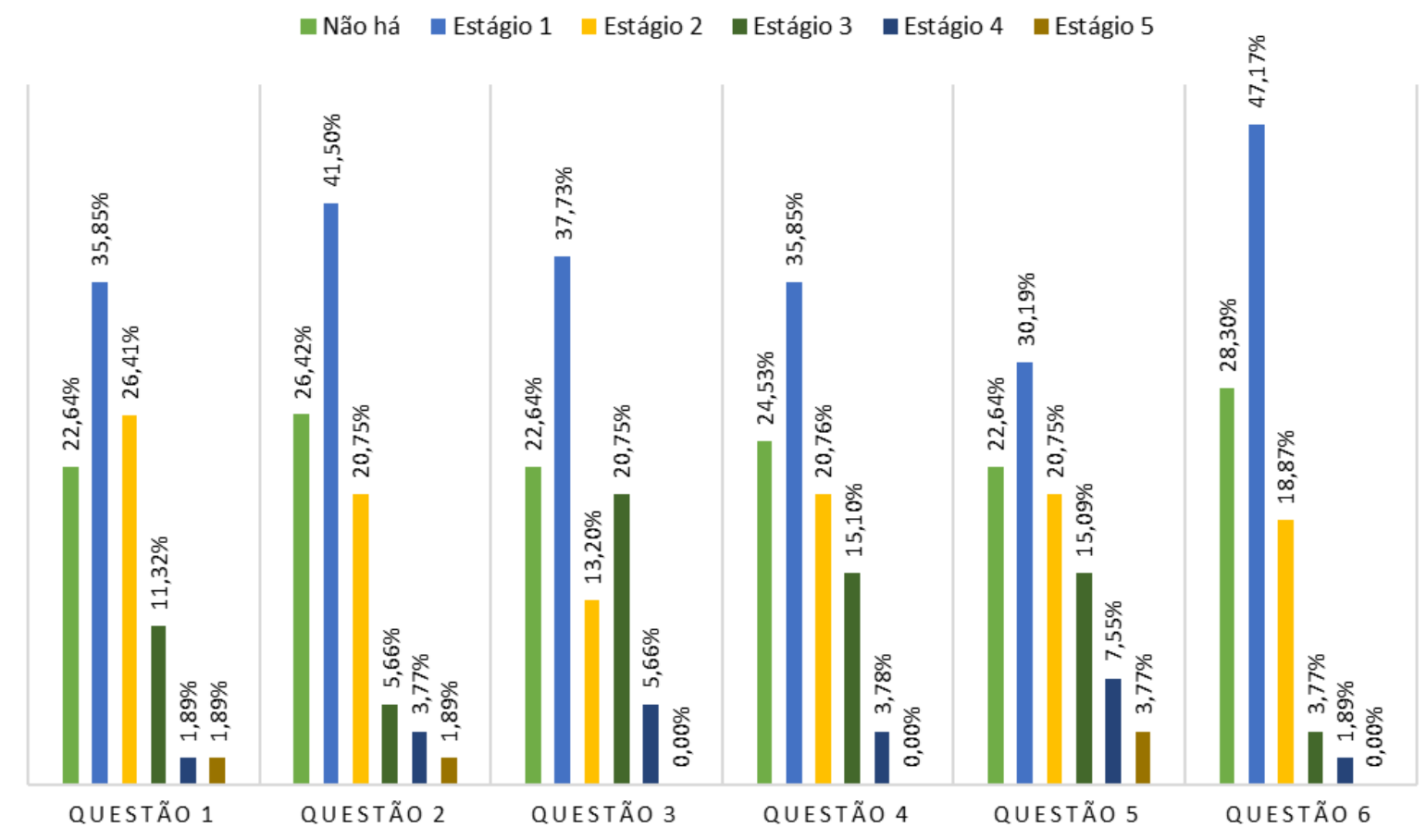

Fonte: Elaborado própria.

Quadro 5 -

Critérios e questões do módulo sociedade.

\begin{tabular}{|l|l|}
\hline \multicolumn{1}{|c|}{ Critério } & \multicolumn{1}{|c|}{ Questão } \\
\hline S.1 - Metas & $\begin{array}{l}\text { A organização procura se envolver em uma série de atividades sociais e } \\
\text { apoia, assim, a atenção, conhecimento e atividades relativas ao } \\
\text { desenvolvimento sustentável em toda a sociedade. }\end{array}$ \\
\hline S.2 - Metodologia & $\begin{array}{l}\text { Uma seleção cuidadosa é feita dos métodos que são usados para a } \\
\text { interação com parceiros sociais. }\end{array}$ \\
\hline $\begin{array}{l}\text { S.3 - Sensibilização e } \\
\text { aprendizado }\end{array}$ & $\begin{array}{l}\text { As interações sociais são usadas para aumentar a sensibilização quanto } \\
\text { à sustentabilidade, tanto dos funcionários e estudantes, quando dos } \\
\text { indivíduos, grupos e instituições da sociedade. Assim, as interações são } \\
\text { à base do aprendizado social e da criação de novas visões em } \\
\text { desenvolvimento sustentável. }\end{array}$ \\
\hline $\begin{array}{l}\text { S.4 - Participação } \\
\text { Temática }\end{array}$ & $\begin{array}{l}\text { Quanto à variedade de temas e questões vigentes a respeito do } \\
\text { desenvolvimento sustentável, a organização participa ativamente de } \\
\text { debates públicos e outras atividades públicas. }\end{array}$ \\
\hline S.5 - Conexão & $\begin{array}{l}\text { Um objetivo básico das interações sociais é conectar as pessoas, } \\
\text { instituições e temas um com os outros, com o objetivo de reforçar a } \\
\text { participação social de indivíduos e grupos da sociedade, e para que seja } \\
\text { possível contribuir efetivamente para questões complexas do } \\
\text { desenvolvimento sustentável. }\end{array}$ \\
\hline $\begin{array}{l}\text { S.6 - Avaliação do } \\
\text { impacto }\end{array}$ & $\begin{array}{l}\text { A organização e seus parceiros sociais investigam o impacto das suas } \\
\text { interações, não apenas neles mesmos, mas também no restante da } \\
\text { sociedade e ambiente natural. }\end{array}$ \\
\hline
\end{tabular}

Fonte: Roorda (2009). 
O critério S.1 aponta o envolvimento da universidade com as atividades sociais ou mesmo se há apoio institucional às atividades relacionadas ao desenvolvimento sustentável e se o conhecimento gerado é compartilhado. Ainda que se observe prevalência de respostas com baixo valor, estágios 0 e 1, 11\% indicaram estágio 3 . Isso significa que as interações estão baseadas em análises dos colaboradores, ou seja, direcionadas por diagnósticos e demandas.

O critério S.2 trata da seleção de métodos para interagir com a sociedade, especialmente a comunidade externa. Para os gestores os eventos ou ações ocorrem uma vez a cada semestre ou não possuem um método específico, de modo que essa escolha é definida pelos que as executam. Cabe destacar que alguns eventos se repetem e acabam proporcionando alguma interação com a comunidade externa, estágio 2, com 0 Reconcitec.

O critério S.3 analisa a Sensibilização e aprendizado de estudantes e servidores, pois se espera que as interações sociais aumentem a sensibilização para a sustentabilidade e sirvam de base ao aprendizado social. Embora a maioria tenha apontado estágio 1, nota-se que o estágio 3 recebeu mais de $20 \%$ das respostas, ou seja, atuam para aumentar a sensibilização, conhecimento e envolvimento.

O critério S.4, Participação temática, trata da variedade de temas e questões que a IES participa em debates públicos ou outras atividades ligadas ao desenvolvimento sustentável. Há predomínio de respostas para o estágio 1, com iniciativas individuais, havendo pouca interação com a sociedade.

O critério S.5 reflete a Conexão entre pessoas, instituição e temas com o objetivo de fortalecer a participação da comunidade no processo de formação para o desenvolvimento sustentável. Para $30,19 \%$ dos gestores há ações que contribuem diretamente para participação ativa das pessoas. Outros $26 \%$ apontaram notas elevadas: estágio 3,4 ou 5 .

No último critério do Módulo sociedade, Avaliação do impacto, 75\% entenderam que a universidade está em estágio inicial, estágios 0 ou 1, de investigação do impacto de suas ações. Também não há uma visão global da IES, nem mesmo organização das informações sobre atividades sociais relacionadas à sustentabilidade.

Em linhas gerais, a avaliação deste módulo sugere existir consciência e visão institucional sobre as parcerias da universidade com a comunidade em muitos aspectos, mas são esparsas ou limitadas aquelas iniciativas ligadas ao campo da sustentabilidade. A Pró-Reitoria de Extensão cadastrou, entre 01 de janeiro de 2018 e 30 de novembro de 2019, 153 projetos de extensão contemplando algum aspecto ambiental ou de sustentabilidade ligados ao Campus Central. Porém, Almeida et al (2019) afirmam ser complexo verificar se tais projetos estão realmente voltados à sustentabilidade, pois se trata de tema transversal, objeto de estudo em todos os cursos. Os autores apontaram que em 2017 foram cadastradas 166 atividades de extensão vinculadas ao campus central, mas apenas 34 ações diretamente ligadas à área meio ambiente, que predominantemente concentra projetos voltados à sustentabilidade.

Perante o exposto parece que os resultados obtidos a partir do instrumento Aishe apontam para a necessidade de uma reorganização administrativa institucional, de modo que o desenvolvimento sustentável seja melhor trabalhado e incorporado em todas as ações do campus, considerando inicialmente atividades que envolvam os servidores e 
discentes. Entretanto, destacam-se dois desafios já apontados por Gazzoni et al (2018): a diferença nas percepções sobre sustentabilidade e a falta de definição única de desenvolvimento sustentável, e a variável imagem de desenvolvimento sustentável entre as diferentes partes da universidade e entre os diferentes indivíduos.

Essas dificuldades de entendimento sobre sustentabilidade estão frequentemente presentes na alta administração das IES, fazendo com que questões essenciais relacionadas ao assunto não recebam a atenção necessária devido à burocracia, sendo tratadas como simples processo administrativo, limitado pelos interesses econômicos (Brandli, 2012).

\section{Considerações finais}

Neste momento os resultados sugerem que a IES seja enquadrada no estágio 1, sem uma sólida identidade da sustentabilidade universitária. Em parte, isso decorre de uma política institucional que até então não contemplava específicas políticas de sustentabilidade, quase ausentes na construção da identidade institucional e PDIs anteriores.

Cabe destacar que o Módulo pesquisa pode contribuir de forma rápida para melhorar esse cenário, especialmente se algumas pesquisas forem também aplicadas ao contexto da própria IES. Apesar da existência de especialistas na área ainda são escassas a aplicabilidade de resultados e produtos de pesquisa no contexto do próprio campus central. O Módulo ensino ainda é tratado de forma individualizada, mas espera-se que a reformulação do conjunto de projetos pedagógicos possa trazer novos olhares e maior preocupação com a sustentabilidade. Certamente que o Módulo extensão terá grande interação com o Módulo ensino, dada a necessidade de curricularização da extensão.

É imperativo que a IES incorpore princípios e práticas de sustentabilidade em todas as suas atividades, dada a crescente pressão para que as organizações adotem políticas sustentáveis e atitudes que contribuam ao meio ambiente, sociedade, economia e cultura. A gestão precisa vislumbrar passos tangíveis para alcançar melhores resultados, ora apontando o caminho, ora atribuindo responsabilidades aos agentes incumbidos para tal ação. Tais orientações estão intimamente relacionadas ao Módulo Identidade.

Por fim, a IES vivencia cenário mais promissor, já que o novo PDI incorporou premissas e prazos compatíveis com a Agenda 2030 e a sustentabilidade institucional é princípio fundante do novo PDI. Então, espera-se que a IES possa se firmar ao mesmo tempo como contemporânea, aberta, integradora, focada nos problemas e demandas, aberta a inovações e a uma nova mentalidade.

\section{Referências}

ALMEIDA, Renato; SOUZA, Tais Teixeira de; GALVÃO, Ariel Santiago da Silva; CERQUEIRA, Mateus Ribeiro de Jesus; SILVA, Naiane dos Santos. Desafios à sustentabilidade em um instituição de ensino superior na Bahia. Revista Eletrônica de Gestão e Tecnologias Ambientais, v. 7, 2019, p. 1-15.

ARAÚJO, Selma Maria de; FREITAS, Lúcia Santana de; ROCHA, Vânia Sueli Guimarães. Gestão ambiental: práticas sustentáveis nos campi de uma lfes. Reunir - Revista de Administração, Contabilidade e Sustentabilidade, v. 7, n. 3, 2017, p. 36-50.

\begin{tabular}{|l|l|l|l|l|l|}
\hline Regae: Rev. Gest. Aval. Educ. & Santa Maria & v. 10 & n. 19 & e65694, p. 1-22 & 2021 \\
\hline
\end{tabular}


ASSIS, Isaac Celestino; LAUS-GOMES, Victor. Educação, identidade e pastoralidade: a estratégia em uma instituição confessional de ensino superior. ECCOM, v. 11, n. 22, 2020, p. 253-266.

BIZERRIL, Marcelo Ximenes Aguiar; ROSA, Maria João; CARVALHO, Teresa; PEDROSA, Júlio. A sustentabilidade socioambiental no ensino superior: um tema integrador para os países de língua portuguesa? Revista da Forges, Lisboa, v. 2, $\mathrm{n}$. 2,2015, p. 99-115.

BIZERRIL, Marcelo Ximenes Aguiar; ROSA, Maria João; CARVALHO, Teresa. Construindo uma universidade sustentável: uma discussão baseada no caso de uma universidade portuguesa. Avaliação: Revista da Avaliação da Educação Superior, v. 23, 2018a, p. 424-447.

BIZERRIL, Marcelo Ximenes Aguiar; ROSA, Maria João; CARVALHO, Teresa; PEDROSA, Júlio. Sustainability in higher education: a review of contributions from Portuguese Speaking Countries. Journal of Cleaner Production, v. 171, 2018b, p. 600-612.

BRANDLI, Luciana Lordelo; FRANDOLOSO, Marcos Antonio Leite; FRAGA, Kéllen Tolotti; VIEIRA, Letícia Canal; PEREIRA, Luiz Adriel; RIGON, Magali Rejane. Indicadores de sustentabilidade ambiental da Universidade de Passo Fundo. Revista CIATEC-UPF, v. 3, 2011, p. 22-35.

BRANDLI, Luciana Lordelo; FRANDOLOSO, Marcos Antonio Leite; FRAGA, Kéllen Tolotti; VIEIRA, Letícia Canal; PEREIRA. Avaliação da presença da sustentabilidade ambiental no ensino dos cursos de graduação da Universidade de Passo Fundo. Avaliação, Campinas, v. 17, n. 2, 2012, p. 433-454.

DELORS, Jacques et al. Educação: um tesouro a descobrir: relatório para a Unesco da Comissão Internacional sobre Educação para o Século XXI. São Paulo: Cortez; Brasília: Unesco, 2003.

DISTERHEFT, Antje; CAEIRO, Sandra Sofia Ferreira Silva; RAMOS, Maria do Rosário; AZEITEIRO, Ulisses Manuel de Miranda Azeiteiro. Environmental management systems (EMS) implementation processes and practices in European higher education institutions top-down versus participatory approaches. Journal of Cleaner Production, v. 31, 2012, p. 80-90.

DOTTO, Dalva Maria Righi; FELTRIN, Schirmer Feltrin; DENARDIN, Adriele Carine Menezes; RUIZ, Lúcio de Medeiros. Sustentabilidade em organizações públicas: estudo de uma instituição federal de ensino brasileira. Rev. Gest. Ambient. Sustentabilidade GeAS, v. 8, n. 2, 2019, p. 235-259.

GAZZONI, Fernando; SCHERER, Flavia Luciane; HAHN, Ivanete Schneider; CARPES, Aletéia de Moura; SANTOS, Maríndia Brachak. O papel das IES no desenvolvimento sustentável: estudo de caso da Universidade Federal de Santa Maria. Revista Gestão Universitária na América Latina - GUAL, v. 11, n. 1, 2018, p. 1-23.

HATCH, Mary Jo; SCHULTZ, Majken (eds.) Organizational identity a reader. Orford: Oxford University, 2004.

KITZMANN, Dione; ASMUS, Milton. Ambientalização sistêmica: do currículo ao socioambiente. Currículo sem Fronteiras, v. 12, n. 1, 2012, p. 269-290.

LICÓRIO, Angelina Maria de Oliveira; SIENA, Osmar; SOUZA, Jonimar da Silva; BORCHARDT, Marcos Aurélio. Estudo sobre sustentabilidade em IES da Amazônia brasileira. Sustentabilidade ambiental-econômica-social: reflexões acadêmicas. 
COLÓQUIO INTERNACIONAL DE GESTÃO UNIVERSITÁRIA, 15, 2015. Anais ... Mar del Plata: Cigu, 2015.

LOZANO, Rodrigo. Incorporation and institutionalization of SD into universities: breaking through barriers to change. Journal of Cleaner Production, v. 14, 2006, p. 787-796.

MARCOMIM, Fátima Elizabeti; SILVA, Alberto Dias Vieira. A sustentabilidade no ensino superior brasileiro: alguns elementos a partir da prática de educação ambiental na universidade. Contrapontos, Itajaí, v. 9, n. 2,2009, p.104-117.

MINAYO, Maria Cecília de Souza (org.). Pesquisa social: teoria, método e criatividade. 18 Petrópolis: Vozes, 2001.

ROORDA, Niko. Aishe - Auditing instrument for sustainability in higher education. 1st edition. Amsterdam: Dutch Committee on Sustainable Higher Education, 2001. Disponível em: http://www.sustainabilityexchange.ac.uk/files/aishe-book1_5.pdf. Acesso em: 10 set. 2019.

ROORDA, Niko. Aishe - Auditing instrument for sustainability in higher education. 2nd edition. Amsterdam: Stichting Duurzaam Hoger Onderwijs (DHO), 2009. Disponível em: https://niko.roorda.nu/books/aishe/. Acesso em: 10 set. 2019.

ROORDA, Niko. The sustainability strategy of Auas. Não publicado, recebido em 2019 através de uma mensagem de email pessoal do autor. Disponível em: https://niko.roorda.nu. Acesso em: 11 out. 2019.

VELAZQUEZ, Luiz et al. Sustainable university: what can be the matter? Journal of Cleaner Production, Knoxville, v. 14, 2006, p. 810-819.

Leandro Barreto de Souza é servidor público federal na Universidade Federal do Recôncavo da Bahia.

Orcid: https://orcid.org/0000-0002-3481-0795.

Endereço: Rua Rui Barbosa, 710 - 44550-000 - Cruz das Almas - BA - Brasil.

E-mail: barretoleo@ufrb.edu.br.

Renato de Almeida é docente na Universidade Federal do Recôncavo da Bahia.

Orcid: https://orcid.org/0000-0002-1242-3495.

Endereço: Rua Rui Barbosa, 710 - 44550-000 - Cruz das Almas - BA - Brasil.

E-mail: renato.almeida@ufrb.edu.br.

Lidiane Mendes Kruschewsky Lordelo é docente na Universidade Federal do Recôncavo da Bahia.

Orcid: https://orcid.org/0000-0003-2396-7217.

Endereço: Rua Rui Barbosa, 710 - 44550-000 - Cruz das Almas - BA - Brasil.

E-mail: lidiane@ufrb.edu.br. 
Critérios de autoria: o trabalho teve início com a pesquisa de mestrado de Leandro, na qual o mesmo coletou os dados com gestores da Universidade. Ao apresentar os resultados, Renato e Lidiane se sentiram motivados a escrever o texto devido a relevância da temática. Os autores desde o início discutiram os rumos da pesquisa e os resultados que foram surgindo. Leandro foi responsável pela coleta, descrição e análise dos dados. Renato e Lidiane participaram da análise dos dados, bem como da concepção e execução. Todos os autores participaram da redação do texto.

Recebido em 7 de maio de 2021.

Aceito em 30 de julho 2021.

(c) $($ i) $(3)$ 